\title{
Challenges and Difficulties of Young Orphans in Tirana in Search of Employment
}

\section{Orneda Gega (Hoxha)}

\author{
Faculty of Social Sciences, University of Tirana; Email: ornedagega@gmail.com
}

\author{
Doi:10.5901/ajis.2016.v5n2p137
}

\begin{abstract}
This study aims to present a parallel between the opportunities provided to the young orphans by the state in order to find employment on one hand and the efforts made by the orphans themselves for employment on the other hand. Research question: - What are the challenges and difficulties faced by the orphans in search of employment? In order to realize this article we used various sources, including the Albanian legislation pertaining to this issue, studies which involved this target group as well as information accessed from the Internet. This article is based on a quantitative research conducted in the city of Tirana. The method used for data collection includes data collected in the field and from questionnaires completed by young orphans who live in secondary school dormitories in Tirana. The study revealed that the chances for employment offered by legislation to young orphans and also support services provided by the state for these orphans have a particular impact on their employment. The study concludes that the categories of orphans face unemployment as a result of the lack of support services by the state. Furthermore, failure to comply with the legislation has led orphans in a vicious circle of suffering, social exclusion, unemployment and hard living conditions.
\end{abstract}

Keywords: unemployment, young orphan, Albanian legislation, support services

\section{Introduction}

Nowadays, one of the current issues worldwide is the engagement of all the societies and their governing mechanisms in creating a world fit for children, where they begin life in the best way possible, and where everyone has various opportunities to develop their individual skills in a healthy and encouraging environment. It is precisely this environment that should serve as a catalyst for the physical, psychological, spiritual, social, emotional and cultural development of children as an issue that has already gained global priority (Special report "On the rights of orphan children, including children living in residential institutions of social care and children's rights when they are exploited through work, Tirana, April 2013). Services for institutionalized children should function even after they are not part of these institutions any more, based on the fact that the number of institutionalized children worldwide has doubled, compared to the decade from 1994 to 2004, leading to eight million (2003) children who live all over the world (Save the Children for : Journal of Sustainable Development in Africa (Volume 13, No.8, 2011) "Re-integration of institutional ised children into society: a case study of Zzimbabwe" E.Muguwe, F.C. Taruvinga, Manyumwa,E and N. Shoko Midlands State University, Faculty of Education, Department of Educational Foundations). If you turn your attention to the Albanian reality, you will learn that the number of orphans across the country is $32,000.400$ of them are actually treated in 10 residential centers that are under the state jurisdiction and 360 others in 16 nongovernmental (NGO) (http://www.revistashtypi.al/) residential centers. Albanian reality presents a society where social problems are acute and the welfare and the environment in which we live are issues that affect us day after day. It also points out the need for state-society multifaceted intervention every day, where different layers and vulnerable social categories, require equity and integration with the rest of society(.Data accessed from Save the Children for : Journal of Sustainable Development in Africa (Volume 13, No.8, 2011) "Re-integration of institutionalised children into society: a case study of Zimbabwe" E.Muguwe, F.C. Taruvinga, Manyumwa,E and N. Shoko Midlands State University, Faculty of Education, Department of Educational Foundations) Let us present in a simplified form through the following graph which are the care services for children without parental care: 


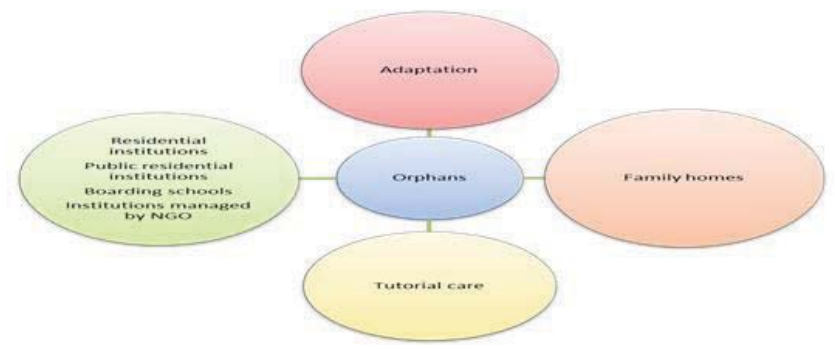

After spending their life in institutions, orphan children are forced to face the reality behind those doors where they spent their childhood. This study aims to present a parallel between the opportunities provided to the young orphans by the state in order to be employed on one hand and the efforts made by the orphans themselves for employment on the other hand. The research question we will try to answer in this paper is: What are the challenges and difficulties faced by the orphans in search of employment?

\section{The Findings of the Study}

\subsection{General Information}

The questionnaire is administered to young orphans who live in secondary school dormitories in Tirana. We surveyed 20 of them and asked them to provide data related to their employment and income. More specifically, we interviewed 10 young women and 10 young men. 9 of them were married and 11 were single. Regarding the age of the respondents it ranged from 23-50 years old.

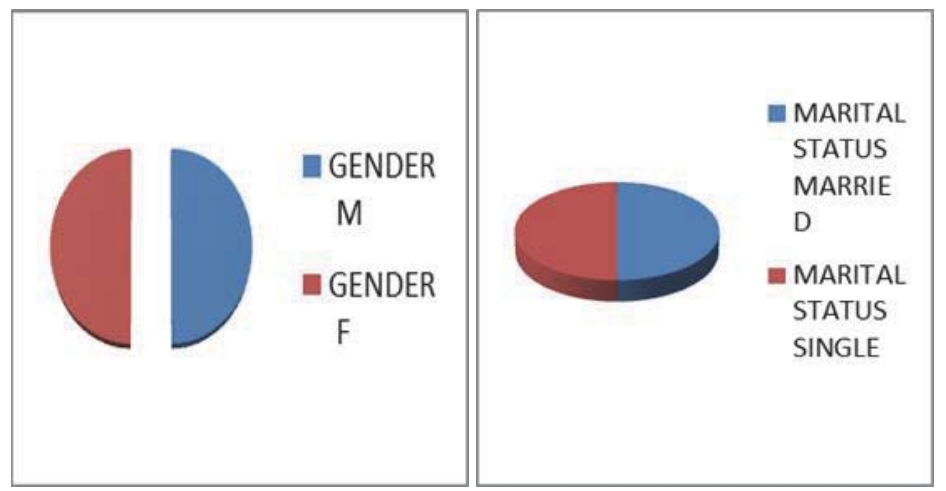

At the end of the penultimate school year, institutions that provide care for orphans, including educational institutions, are required to send to the Ministry of Labour and Social Affairs, as well as to local authorities for social services exact statistics, so that are taken measures to provide housing and employment for the orphans ${ }^{1}$. But the reality speaks otherwise. This results from the answers provided to the following question:

Question: Do you have a job? to having a job.

The majority of the young orphans said that they were not in a working relationship (80\%) and only $20 \%$ admitted 


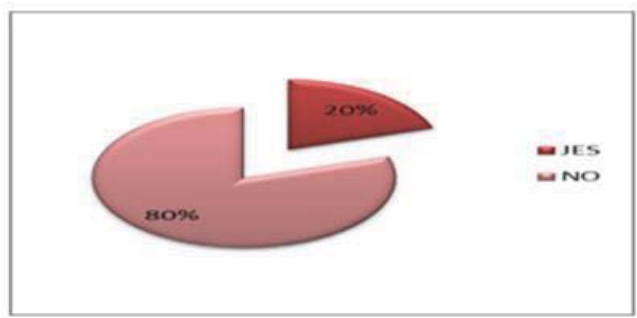

Those individuals that already were employed (i.e. 20\%) were asked about the sector in which they worked. As you can see from the graph, all answered that they worked in the public sector. full-time.

Regarding the form of employment (full-time or part-time), the answers indicated they were all employees working
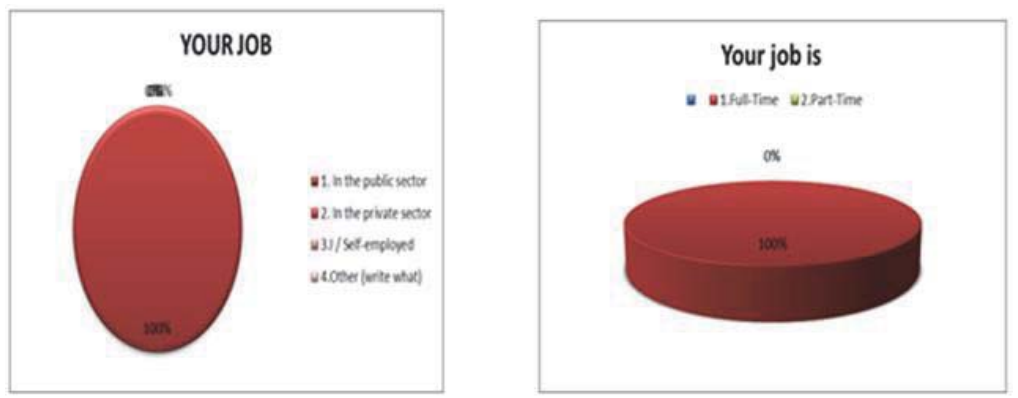

Question: What are the reasons you are not working?

Most of the respondents (50\%) have chosen the option OTHER. Among the reasons they mention are: I have stolen in the latest job I have done, the profession that I have (tailor) is not appropriate for men, I have a child, I cannot find a job, or there are no jobs available. $25 \%$ of them responded that they do not have enough education 2 ; it happens because many orphans drop out of school, or attend school at irregular intervals, which leads to reduced chances for future employment ${ }^{3}$. Whereas the last $25 \%$ responded that they do not have a profession. Options like: I do not want to work, I have sufficient income to make the living, were not selected by any of the respondents.

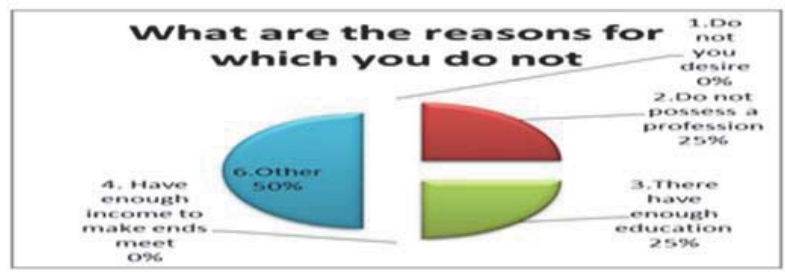

Concerning the sources of income used by the orphans for their living, the most mentioned resulted the following: Economic assistance $e^{4}(50 \%)$; Wages (20\%); Donations from friends (15\%), other (10\%); Invalidity pension (5\%).

\footnotetext{
2 Source" the declaration of Mr. Kadria Alia posted by Rhea "There are 3,800 orphans who do not attend school because they have no food, clothing or books", "Not just a day for orphans" 20/05/2014

${ }^{3}$ Amnesty International, November 2007 Albania "No home no life" - Orphans and the right for housing.

${ }^{4}$ Note: Based on Law nr.9355 date 10.03.2005 "On social services and Aid" and DCM nr.787 date 14.12.2005 On the criteria, procedures and amount of economic assistance" welfare recipients included among others include: o Unemployed orphans, over 25 


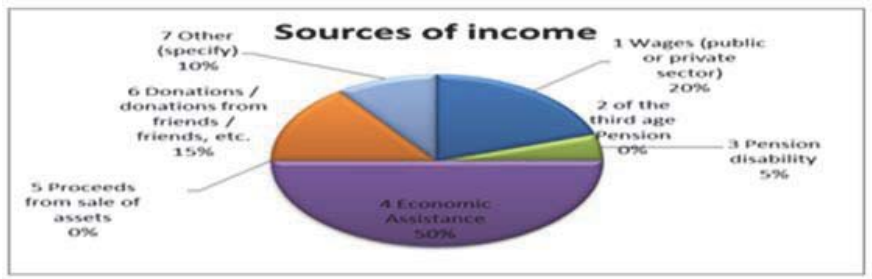

Question: What is your family monthly income? $50 \%$ of the respondents answered that they live with less than 10,000 lek. None of them reported having incomes above 50,000 lek.

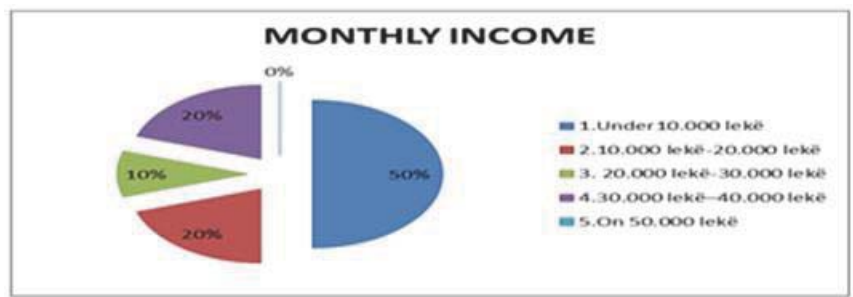

Question: What do you spend your income for? The answer that prevails is that incomes of the orphans are spent on food (53\%) and clothing (42\%).

Question: Which of the following actors do you hold more responsible for your unemployment? Only $25 \%$ of respondents held themselves responsible for being unemployed, whereas the vast majority (more specifically $75 \%$ ) made the state responsible for their unemployment.

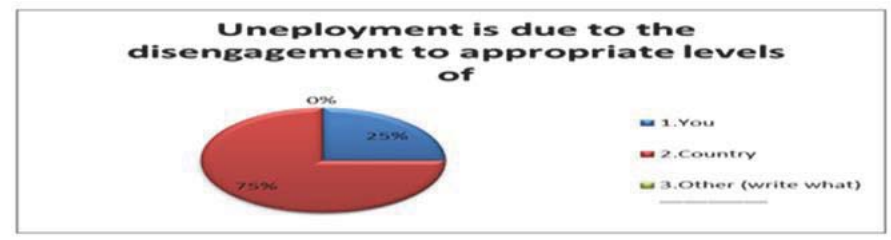

For many developing countries, high rates of poverty and lack of resources available to ensure its general and / or mandatory education for children is often a double-edged sword. Education is a key factor in overcoming poverty and disease. It can provide a higher standard of living; can offer more resources and opportunities to help people overcome poverty. However, getting an education while you live in poverty can often be difficult due to poor living conditions, lack of resources and lack of opportunities. Poverty is a serious problem which leads to a low school attendance and lower results in school (UNICEF, 2007)5.

After finishing the $9^{\text {th }}$-grade school, the state guarantees full scholarships for orphan children in social care institutions, so they can receive secondary education at a boarding school. Those children who are able and willing to pursue higher education, receive scholarships and free boarding at the university dormitories. Providing care for children who attend secondary schools and higher education is the responsibility of the Ministry of Education and Sciences. If we used the language of numbers, we would find out that there are 311 young orphans between 14-21 years old.

Question: Do you think your level of education is sufficient for you, or you would you like to have a higher

years; o Orphans aged 18- 25 years, who are not placed in social care institutions or foster care. Information accessed from http://www.sherbimi social.gov.al/ndihma-ekonomike/

${ }^{5}$ Curley J, Fred S, Han KC. Assets and educational outcomes: Child Development Accounts (CDAs) for orphaned children in Uganda. Child Youth Serv Rev. 2010;32:1585-90 
educational level? $95 \%$ of respondents answered that their actual educational level is not sufficient and only $5 \%$ said that they had the right level of education.

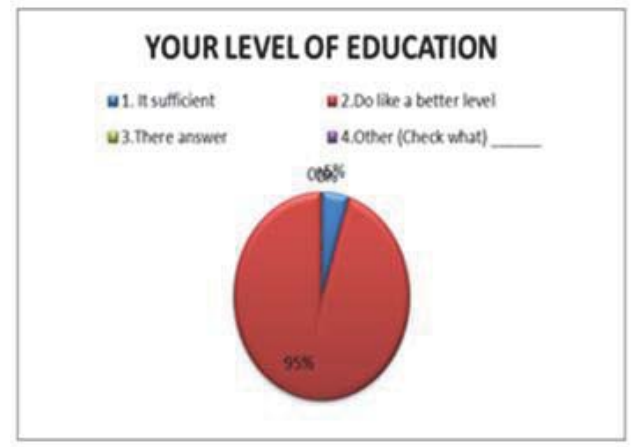

Question: Which of the following actors do you consider more responsible for your education?

Regarding education, contrary to the answers related to employment, most of the respondents held themselves responsible (60\%) and $40 \%$ thought that the state was responsible.

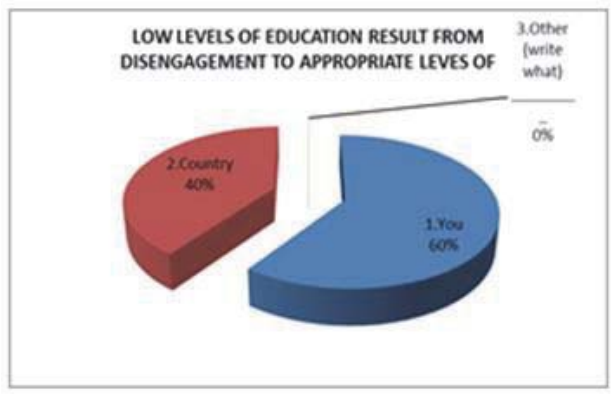

Question: Do you think the state provides help or support services for the unemployed? All the respondents answered that the state does not provide support services for orphans.

Question: Have you participated in professional training offered by the state free of charge?

When we talk about benefiting from support services such as vocational training, most of the orphans report that they do not participate (70\%).
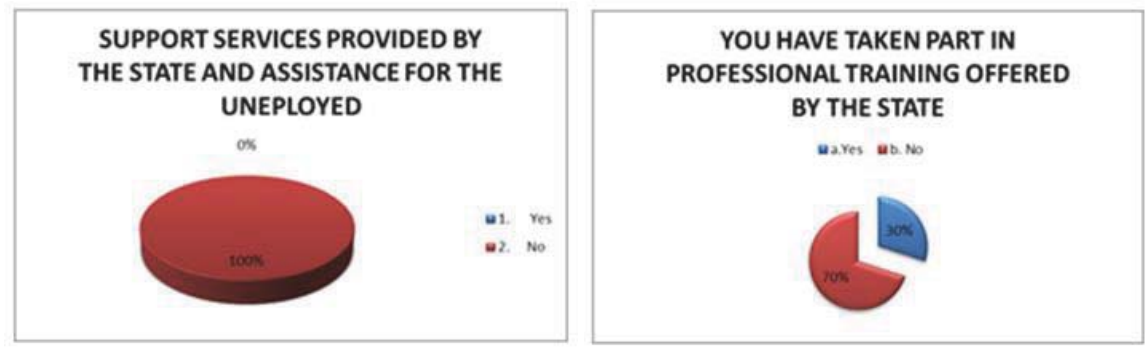

Question: Have you had a job in the last 5 years? During a 5-year periods, half of the young orphans replied to have worked and the other half not. 


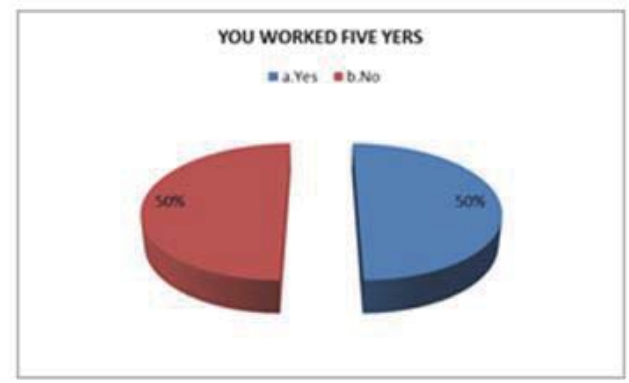

Question: Are you currently looking for a job? For the unemployed, which constituted $80 \%$ of the orphans surveyed, $50 \%$ admitted they were not looking for a job, whereas the other half answered positively, which indicates a level of inactivity.

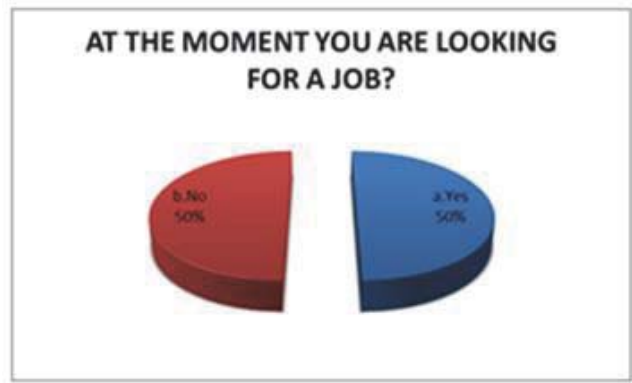

Question: Are you registered in the employment offices as unemployed job seekers?

Most of the orphans not only are unemployed, do not participate in vocational training, do not seek employment, but as you can notice, they do not even register themselves as unemployed job seekers in the employment offices. All of these elements drag young orphans in a vicious circle of suffering, social exclusion, unemployment and low hard living conditions

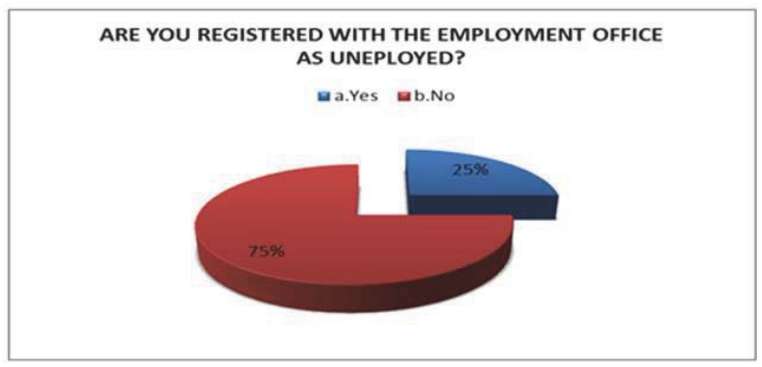

\section{Conclusions}

Orphans face many difficulties in terms of employment and income benefits. As a result of economic hardships and unemployment, the latter is also linked with low monthly incomes they live with. All these factors lead to hard living conditions orphans have to cope with and low incomes they use mostly for food and clothing. Also young orphans lacked education and therefore they had difficulties in getting employed. This was noticed from their answers where most of them (95\%) said they were dissatisfied with their level of education. Lack of education and vocational training and as a result lack of employment limit and impoverish furthermore this category in need not allowing them to come out of the vicious circle. On the other hand, poverty and lack of social support hinder their education further on, making it much 
more difficult to improve conditions. But what we find striking is that on the one hand the orphans make the state responsible for their unemployment but on the other hand most of them did not participate in professional training, not relying on the support services provided by the state. Also they are not registered as unemployed at employment offices and are not looking for work. They somehow excuse themselves from the fact that they were unemployed and leave all this responsibility to the state. It remains to be said that the two parties should cooperate with each other. The state should amend its legislation on "Status of Orphans" and should realize everything written on that document, whereas the young orphans must try to escape from the vicious circle that has involved them and hold responsible for their situation not only the state but also themselves. Collaboration between the state and the orphans could bring a positive outlook for this category of individuals.

\section{Glossary of Terms}

Institution - public or social body, which develops its activity in a particular area of the economy, science, education, culture, social life, political life etc.

Residential institutions - of social care, constitute structures which provide child care for children without parental care. Life in these institutions is organized following the group model, not the family way of life, where paid staff takes care for children. These structures may be community-based that accommodate children without parental care from the surrounding community, or may be national residential institutions, which provide care for children who come from various communities.

An orphanage (http://en.wikipedia.org/wiki/Orphanage) - is a residential institution devoted to the care of orphans children whose biological parents are deceased or otherwise unable or unwilling to care for them. Biological parents, and sometimes biological grandparents, are legally responsible for supporting children, but in the absence of these, or other relatives willing to care for the children, they become a ward of the state, and orphanages are one way of providing for their care, housing and education.

Orphan - is a parentless child, up to age of 25, as specified in the Status of the Orphan. (Republic of Albania Law nr. 9355, date 10. 03. 2005 "Aid and Social Services") In the category of orphans or children without parental care are included children aged 0-14 and adolescents 14-18, who do not live with their parents due to: the death of both parents; waiver of parental custody or abandonment; parents' temporary or permanent disability to take care (sickness or serving a sentence of imprisonment); establishment of care from the administrative structures (social services); deprivation of parental rights (based on a final decision given by the court).

Integration (Decision of the Council of Ministers "On some amendments to the decision of the Council of Ministers $n r 80$ date 28.01.2008 "On the approval of the sectorial strategy of social protection and the action plan for its implementation" 2008) - represents the establishment of the system of institutions and the design of policies that create appropriate environments for placing individuals.

Reintegration - means that children can join their biological relatives or foster families or live their lives, facilitating their final inclusion in society (Journal of Sustainable Development in Africa (Volume 13, No.8, 2011) Re-Integration Of Institutional Ised Children Into Society: A Case Study Of Zimbabwe E.Muguwe, F.C. Taruvinga, Manyumwa,E and N. Shoko Midlands State University, Faculty of Education, Department of Educational Foundations).

Social exclusion - is "a process through which individuals or groups are wholly or partially excluded from full participation in the society in which they live"( Nordic Journal of African Studies 11(1): $93-113$ (2002) Social Exclusion and Inclusion: Challenges to Orphan Care in Malawi Wiseman Chijere Chirwa University of Malawi, Malawi)

\section{References}

Amnesty International, November 2007 Albania "No home no life" - Orphans and the right for housing.

Curley J, Fred S, Han KC. Assets and educational outcomes: Child Development Accounts (CDAs) for orphaned children in Uganda. Child Youth Serv Rev. 2010;32:1585-90

Data accessed from Save the Children për : Journal of Sustainable Development in Africa (Volume 13, No.8, 2011) "Re-integration of institutionalised children into society: a case study of Zimbabwe" E.Muguwe, F.C. Taruvinga, Manyumwa,E and N. Shoko Midlands State University, Faculty of Education, Department of Educational Foundations

Decision of the Council of Ministers "On some amendments to the decision of the Council of Ministers nr 80 date 28.01.2008 "On the approval of the sectorial strategy of social protection and the action plan for its implementation" 2008

http://en.wikipedia.org/wiki/Orphanage

http://www.revistashtypi.al/

Information accessed from http://www.sherbimisocial.gov.al/ndihma-ekonomike/ 
Journal of Sustainable Development in Africa (Volume 13, No.8, 2011) Re-Integration Of Institutional Ised Children Into Society: A Case Study Of Zimbabwe E.Muguwe, F.C. Taruvinga, Manyumwa,E and N. Shoko Midlands State University, Faculty of Education, Department of Educational Foundations

Law Nr. nr.8153, date 31.10.1996, "On the Status of Orphans"

Nordic Journal of African Studies 11(1): 93-113 (2002) Social Exclusion and Inclusion: Challenges to Orphan Care in Malawi Wiseman Chijere Chirwa University of Malawi, Malawi Orphans aged 18- 25 years, who are not placed in social care institutions or foster care.

Republic of Albania Law nr. 9355, date 10. 03. 2005 "Aid and Social Services"

Source" the declaration of Mr. Kadria Alia posted by Rhea "There are 3,800 orphans who do not attend school because they have no food, clothing or books", "Not just a day for orphans" 20/05/2014

Special report "On the rights of orphan children, including children living in residential institutions of social care and children's rights when they are exploited through work, Tirana, April 2013 